\title{
Gene Expression Is Not Systematically Linked to Phytoalexin Production During Alfalfa Leaf Interaction with Pathogenic Bacteria
}

\author{
Christophe Sallaud, ${ }^{1}$ Jose Zuanazzi, ${ }^{2}$ Joumana El-Turk, ${ }^{1}$ Juliette Leymarie, ${ }^{1}$ Colette Breda, ${ }^{1}$ \\ Dominique Buffard,, ${ }^{1,3}$ Isabelle de Kozak, ${ }^{1}$ Pascal Ratet, ${ }^{1}$ Philippe Husson, ${ }^{2}$ Adam Kondorosi, ${ }^{1}$ and \\ Robert Esnault ${ }^{1,3}$ \\ ${ }^{1}$ Institut des Sciences Végétales, C.N.R.S., 91198 Gif-sur-Yvette Cedex, France. ${ }^{2}$ Institut de Chimie des \\ Substances Naturelles, C.N.R.S, 91198 Gif-sur-Yvette Cedex, France. ${ }^{3}$ Université Paris 7, Paris, France \\ Received 1 December 1994. Accepted 12 November 1996.
}

\begin{abstract}
During an incompatible interaction between alfalfa leaves and Pseudomonas syringae pv. pisi, flavonoids accumulated between 6 and $24 \mathrm{~h}$, whereas they could not be detected during the first $96 \mathrm{~h}$ of a compatible interaction with Xanthomonas campestris pv. alfalfae. Three flavonoids accumulated which were identified as $4^{\prime}, 7$ dihydroxyflavanone and 4',7-dihydroxyflavone and $2^{\prime}, 4,4^{\prime}$-trihydroxychalcone. Surprisingly, the phytoalexin medicarpin was found only at a very low level. Analysis of both the infected and noninfected zones revealed that these flavonoids were detectable only in the infiltrated tissue. Northern hybridizations showed that transcripts encoding for chalcone synthase (CHS), chalcone reductase, chalcone isomerase, and isoflavone reductase (IFR) accumulated in both infiltrated and noninfiltrated zones. Measurements of the CHS and IFR activities in the infiltrated and noninfiltrated zones indicated that the levels of CHS activity were highly increased only in the infiltrated zones, whereas the levels of IFR were very slightly stimulated. These results suggested that an apparently coordinated expression of genes, involved in both the early and late steps of isoflavonoid biosynthesis, is not a sufficient condition for phytoalexin accumulation and that the fundamental regulatory steps might act at the posttranscriptional level.
\end{abstract}

Additional keywords: CHS and IFR activity, flavonoid biosynthesis, incompatible/compatible interaction, infiltrated/ noninfiltrated tissues.

Phytolaexins are low molecular weight substances, essentially absent from uninfected plant tissues, but accumulating upon infection by pathogenic organisms (Bailey 1982; Darvill and Albersheim 1984). In leaves undergoing a hypersensitive response (HR), phytoalexins accumulate more rapidly and

Corresponding author: R. Esnault

E-mail: ESNAULT@ISV.CNRS-GIF.FR

Present addresses of C. Sallaud, J. Zuanazi, and J. El-Turk: Chulabhorn Research Institute, Bangkok 10210, Thailand; Faculdad de Farmacia, Porto Alegre, Brazil; and Institut Pasteur, Casablanca, Morocco, respectively. reach higher concentrations than in leaves exhibiting a susceptible response. Moreover, it has been shown in numerous papers studying fungal infections (reviewed by Darvill and Albersheim 1984; Collinge and Slusarenko 1987; Templeton and Lamb 1988; Dixon and Lamb 1990) that accumulation of phytoalexins is regulated, at least in part, at the transcriptional level.

Conclusive proof for direct involvement of phytoalexins in the containment of a pathogen in planta is still lacking in spite of numerous reports supporting a role of phytoalexins in the resistance of plants against pathogenic microbes (Mansfield 1982; Nicholson and Hammerschmidt 1992). Several questions have been posed to help to understand the role of phytoalexins in disease interactions. Is their synthesis linked to the expression of resistance? Do they accumulate before or after plant cell death? Are their concentrations within the infection site sufficient to be actually antimicrobial compounds? The demonstrations that, for example, inhibition of the phenylalanine ammonia-lyase activity in soybean led to a loss of resistance against Phytophthora megasperma f. sp. glycinea (Moesta and Grisebach 1982), an accumulation of avenalumins in oat cells associated with the infection site (Mayama and Tani 1982) or of luteolinidin and apigenin in individual cells of sorghum leaves at fungitoxic concentrations (Snyder et al. 1991), are arguments in favor of such a role.

In legumes, phytoalexins belong to the family of isoflavonoids which may act as nod genes inducers in the symbiotic rhizobial partner. In alfalfa, previous studies have implicated medicarpin (synthesized through the 5-deoxyflavonoid branch pathway, Fig. 1) as an important factor in defense against a number of fungal pathogens (Olah and Sherwood 1971; Smith et al. 1971; Higgins 1972; Baker et al. 1989; Latunde-Dada et al. 1987; O'Neill and Sanders 1994); however, no information on phytoalexins induced by pathogenic bacteria has been published. We have previously shown (Esnault et al. 1993) that in alfalfa leaves, the bacterium Pseudomonas syringae pv. pisi induces an HR, whereas the bacterium Xanthomonas campestris pv. alfalfae induces water-soaked lesions leading to the development of the disease. Moreover, we have shown (Esnault et al. 1993; Sallaud et al. 1995b) that during the incompatible interaction four of the genes involved in the flavonoid pathway, i.e., CHS, CHR, CHI, and IFR, are induced 
in an apparently coordinated fashion, while in the compatible interaction their level of expression is significantly lower.

To gain a better understanding of the parameters controlling the defense reaction in this plant, we have undertaken studies aimed at addressing the following questions. First, what is the nature of the flavonoids accumulated in both interactions and is there any production of medicarpin which has been shown as the major isoflavonoid accumulated in cultured cells elicited by a fungal elicitor (Dalkin et al. 1990) and in leaves (Smith et al. 1971) infected with pathogenic fungi? Second, are the flavonoids accumulated within the infection site or/and in the noninfected zone? Third, is there any correlation between the accumulated flavonoids and the expression of the genes involved in the flavonoid biosynthetic pathway? In this paper, we report results pertaining to these questions and suggesting that transcript accumulation is not a sufficient condition for phytoalexin production.

\section{RESULTS}

\section{Analysis of whole leaves.}

Flavonoid accumulation during incompatible and compatible interactions. Leaves, infiltrated with $10 \mathrm{mM} \mathrm{MgCl}_{2}$

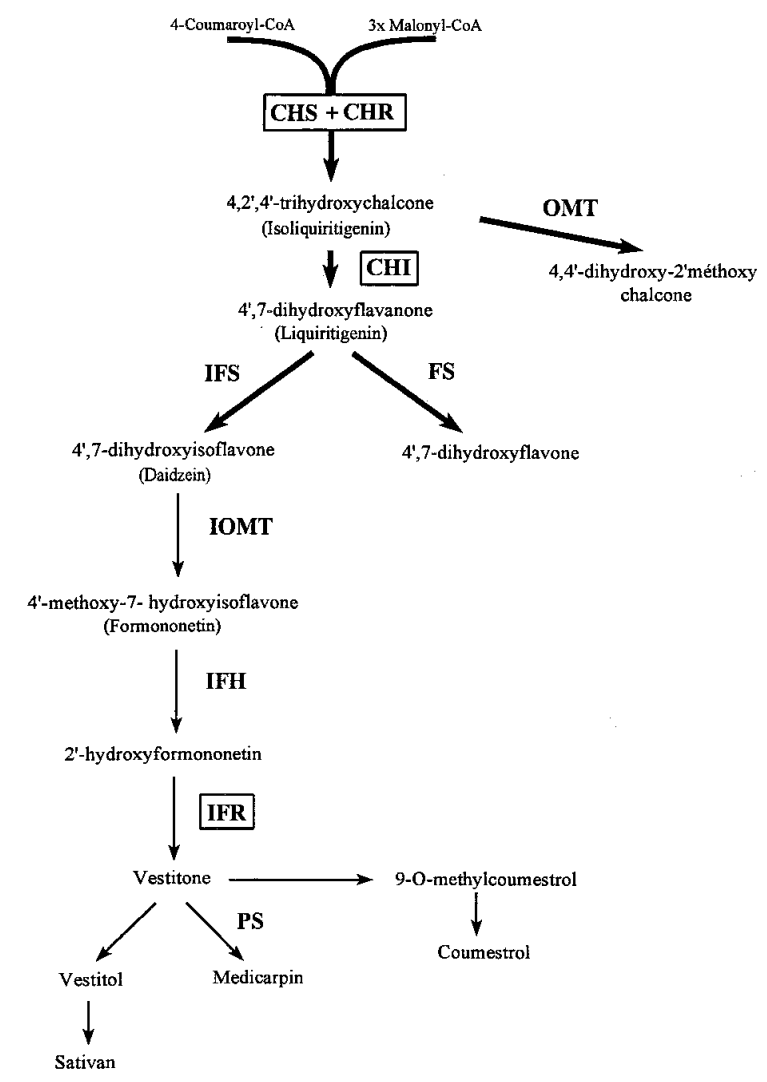

Fig. 1. Schematic representation of the 5-deoxyflavonoid biosynthesis pathway in alfalfa, based on Dewick and Martin (1979a, 1979b) and Martin and Dewick (1980). Abbreviations: CHI, chalcone isomerase; CHR, chalcone reductase; CHS, chalcone synthase; FS, flavone synthase; IFH, isoflavone hydroxylase; IFR, isoflavone reductase; IFS, isoflavone synthase; IOMT, $O$-methyltransferase transfering a methyl group to 7-OH of isoflavone; OMT, $O$-methyltransferase transfering a methyl group to the $2^{\prime} \mathrm{OH}$ of chalcone; PS, pterocarpan synthase. The alfalfa cDNA clones used in this study are boxed. (control) or with a suspension of $P$. syringae pv. pisi or of $X$. campestris pv. alfalfae, were harvested 6, 24, 48, 72, and $96 \mathrm{~h}$ after infiltration. Flavonoids (aglycones and conjugated forms) were extracted and analyzed by HPLC. As shown in Figure $2 \mathrm{~A}$, the profile of the total extract from control leaves revealed 2 major peaks, G2 and G3 and several minor ones, G1, G4, and G5. None of these compounds was identified. To distinguish between the conjugated and the free forms (aglycones) of the flavonoids, extracts containing the aglycones were prepared (see Materials and Methods) and analyzed. No aglycones were detectable in control samples (data not shown), indicating that most of the compounds present in the control leaves were probably conjugated flavonoids, possibly with sugars as described previously for alfalfa leaves by Olah and Sherwood (1971). HPLC profiles equivalent to that of the control were obtained from the total flavonoids (Fig. 2C) and aglycones (data not shown) extracted from leaves infiltrated with $X$. campestris pv. alfalfae (compatible interaction). The apparent increase of the size of peaks G1, G4, and G5 (Fig. 2C) was not significant as we noticed some variations from one experiment to another. The HPLC profile of total flavonoids from leaves infiltrated with $P$. syringae pv. pisi (incompatible interaction) revealed (Fig. 2B) four major (designated as 2 to 5) and two minor (designated as 6 and 7) peaks. Removal of the conjugated flavonoids from the extract obtained from the incompatible interaction allowed us to detect (Fig. 3A) another peak, designated as 1 , which was detected only in these samples. This compound had almost the same retention time as the compound G2 and was hidden in the HPLC profile from the total extract shown in Figure 2; this hypothesis was verified by using a different slope of the elution gradient which allowed separation of these two peaks (Fig. 3B). Several compounds from all these peaks were tentatively identified (through the UV spectrum coupled to HPLC using a photodiode array detector and co-chromatography of standards) as: 4',7-dihydroxyflavanone (liquiritigenin, peak 1), 4',7-dihydroxyflavone (peak 2), 2,4,4'-trihydroxychalcone (isoliquiritigenin, peak 3), formononetin (peak 6), and medicarpin (peak 7), whereas attempts to identify peaks 4 and 5 with authentic standards failed.

To check the above tentative identifications mass spectrometric analyses were conducted on seven independent extracts, three control (infiltrated with $\mathrm{MgCl}_{2}$ ), and four treated (infiltrated with the $P$. syringae suspension) leaves harvested $48 \mathrm{~h}$ after injection and typical results (mass spectra from 100 to $700 M_{\mathrm{r}}$ with a magnification of the 150 to 350 region, approximately) are shown in Figures 4 and 5, respectively. In our experimental conditions, the separated compounds existed mainly as protonated form corresponding to $M_{\mathrm{r}}+1\left(\left[M_{\mathrm{r}}+\mathrm{H}\right]+\right.$ ions). Both control and treated leaves contained compounds with the same $M_{\mathrm{r}}$ (such as 102.4, 202.1, 216.1, 368.2, 468.2, $540.1,568.2$, or 655.2 ). However new peaks, in the range 200 to $300 M_{\mathrm{r}}$, were only detectable in the extracts from leaves undergoing the incompatible interaction (Fig. 5), one of them, with a $M_{\mathrm{r}}$ of 255 , showing a very strong signal. This value corresponds exactly to the expected mass of 4,7'dihydroxyflavone, which was ascertained by analyzing, in the same conditions, the corresponding standard (data not shown). At the magnification used for this figure, some of the minor peaks were clearly distinguishable (for example $M_{\mathrm{r}}$ equal or higher than 286), whereas a peak with a $M_{\mathrm{r}}$ of 257 (which might correspond to the protonated form of the $2^{\prime}, 4,4^{\prime}-$ 
trihydroxychalcone) was just discernible. By focusing, however, on the 240 to 280 region, this peak was systematically detected (data not shown), albeit it was low. Medicarpin $\left(M_{\mathrm{r}}=\right.$ 271 , protonated form) or its immediate precursor, vestitone $\left(M_{\mathrm{r}}=287\right.$, protonated form $)$, were probably present in the analyzed extracts but, as suggested by the data of Figure 3, they did not correspond to abundant molecular species. The compounds of relatively high $M_{\mathrm{r}}$ (equal to or higher than 350) might correspond to some of the glycosylated flavonoids, i.e., peaks G1 to G5, detected in the extracts (Figs. 2 and 3).
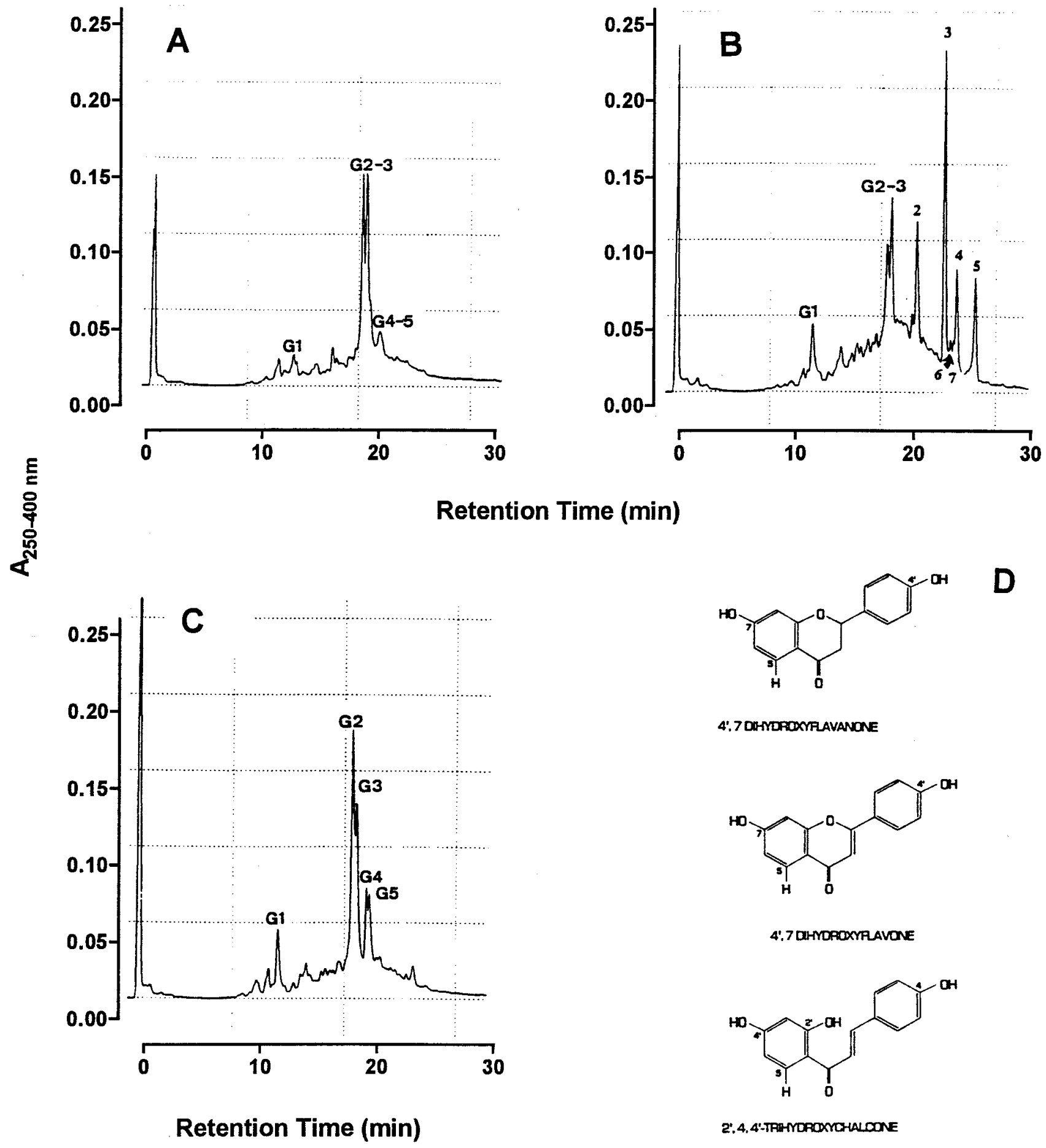<smiles>[2H]C1CC(c2ccc(O)cc2)Oc2cc(O)ccc21</smiles>

4:7 OAMTLROMMLAVANONE<smiles>Oc1ccc(C2=CC(O)c3ccc(O)cc3O2)cc1</smiles>

4:7 DHMDROXYAAVONE<smiles>OC1=CC=C(/C=C/C(O)c2ccc(O)cc2O)CC1</smiles>

2:4,4'TRRMOROOMCHALOONE

Fig. 2. HPLC chromatograms of total extracts from leaves harvested $48 \mathrm{~h}$ after infiltration with $\mathrm{MgCl}_{2}(\mathbf{A})$ or bacteria (B,C) and structure of some isolated and identified compounds (D). A, Control leaves; B, C, leaves infiltrated, respectively, with a suspension of Pseudomonas syringae pv. pisi or Xanthomonas campestris pv. alfalfae, at $10^{9}$ bacteria $\mathrm{ml}^{-1}$. The slope of the gradient used for the chromatographic profiles shown was from 20:80:0.1 to 80:20:0.1 (v/v/v) methanol:water:trifluoroacetic acid in 0 to $60 \mathrm{~min}$. Compounds designated as G1 to G5 corresponded to conjugated forms of flavonoids (unidentified). Identified compounds: peak $2=4^{\prime}, 7$-dihydroxyflavone, peak $3=2^{\prime}, 4,4^{\prime}$-trihydroxychalcone (isoliquiritigenin), peak $6=$ formononetin and peak $7=$ medicarpin. The $A_{200-400 \mathrm{~nm}}$ values, for each compound, correspond to the absorbances measured at the maximum absorbtion value. 
Our data allowed us to conclude that the peaks 1, 2, and 3 specifically detected in the HPLC profiles from incompatible interaction extracts, were 4',7-dihydroxyflavanone, 4',7dihydroxyflavone, and 2',4,4'-trihydroxychalcone, respectively (Fig. 2).

The amounts of these two last compounds were tentatively determined from HPLC analysis of extracts obtained from
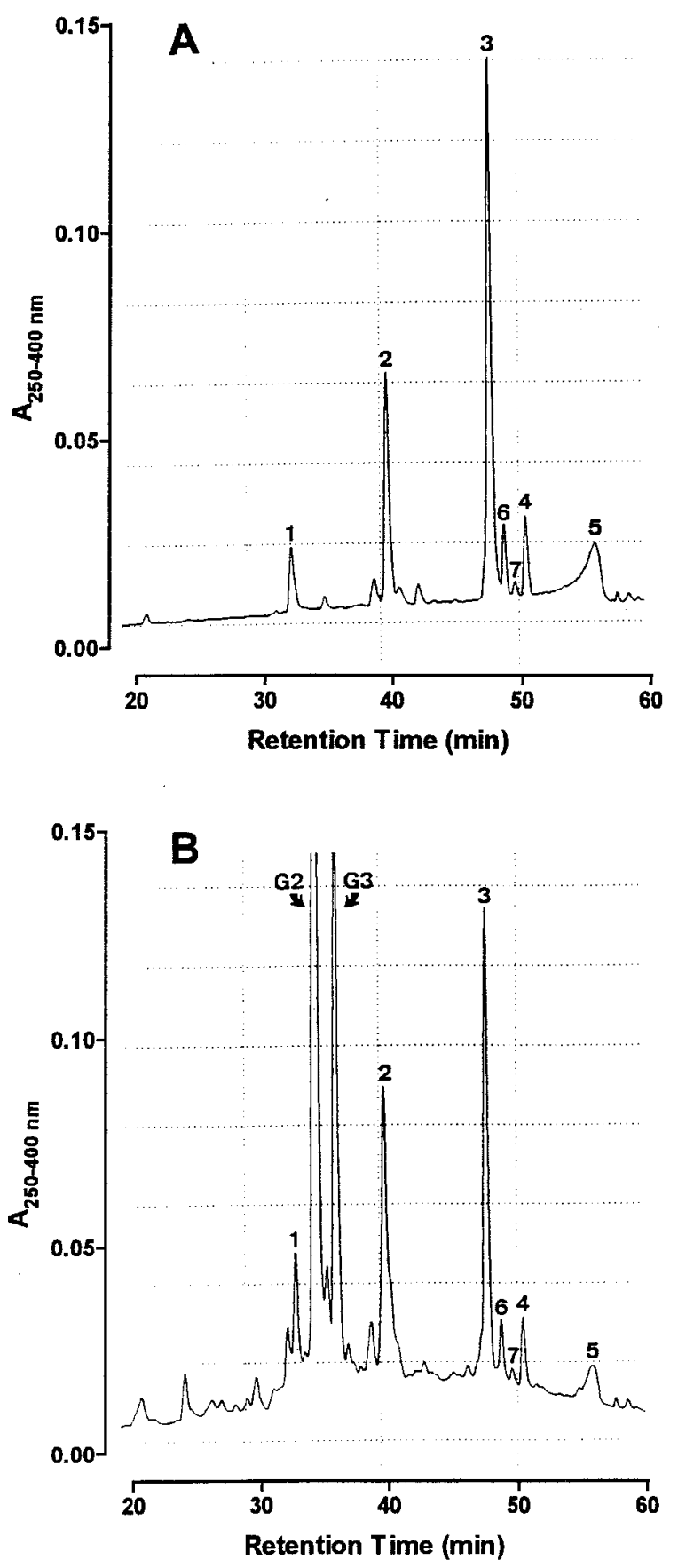

Fig. 3. Comparison of the HPLC chromatograms from aglycones (A) and total flavonoids (B). Extracts were prepared from leaves harvested $48 \mathrm{~h}$ after infiltration with a suspension of Pseudomonas syringae pv. pisi. Conditions and numbering of peaks are as in Figure 2. The slope of the gradient used for the chromatographic profiles shown was from 20:80:0.1 to $80: 20: 0.1(\mathrm{v} / \mathrm{v} / \mathrm{v})$ methanol:water:trifluoroacetic acid in 0 to 90 min. Identified compounds: peak $1=4^{\prime}, 7$-dihydroxyflavanone (liquiritigenin), peaks 2 to 6, as in Figure 2. leaves infiltrated with $P$. syringae pv. pisi and $X$. campestris pv. alfalfae from 6 to $96 \mathrm{~h}$. The size of the area of the peaks was divided by the respective extinction coefficient and the values obtained were used for calculating their relative proportion (expressed as percent of the maximum size of the area); the toal amount measured at $96 \mathrm{~h}$ was $100 \%$. As shown in Figure 6, these compounds began to accumulate only at 6 to $24 \mathrm{~h}$ after infiltration of the $P$. syringae, their respective proportion being equivalent except at the time point $96 \mathrm{~h}$, where the 4',7-dihydroxyflavone was the most abundant. Included in this figure are the curves, based on densitometric readings of Northern blot autoradiograms, corresponding to the time course of CHS transcript levels during the incompatible (A) and compatible (B) interactions, indicating that the flavonoid production was preceded by a transient accumulation (maximum at around $6 \mathrm{~h}$ ) of the CHS transcripts.

Our results showed that the major flavonoids produced during the incompatible interaction belong to the common steps of the pathway, i.e., before the branching step, allowing us to conclude that the isoflavonoid branch of the 5deoxyflavonoid biosynthetic pathway was either not activated or only at a very low level.

\section{Analysis of the infiltrated vs. the noninfiltrated leaf zones in the incompatible interaction.}

As described in Materials and Methods, the infiltrated zone was defined as the infiltrated area per se plus the 1 to $2 \mathrm{~mm}$

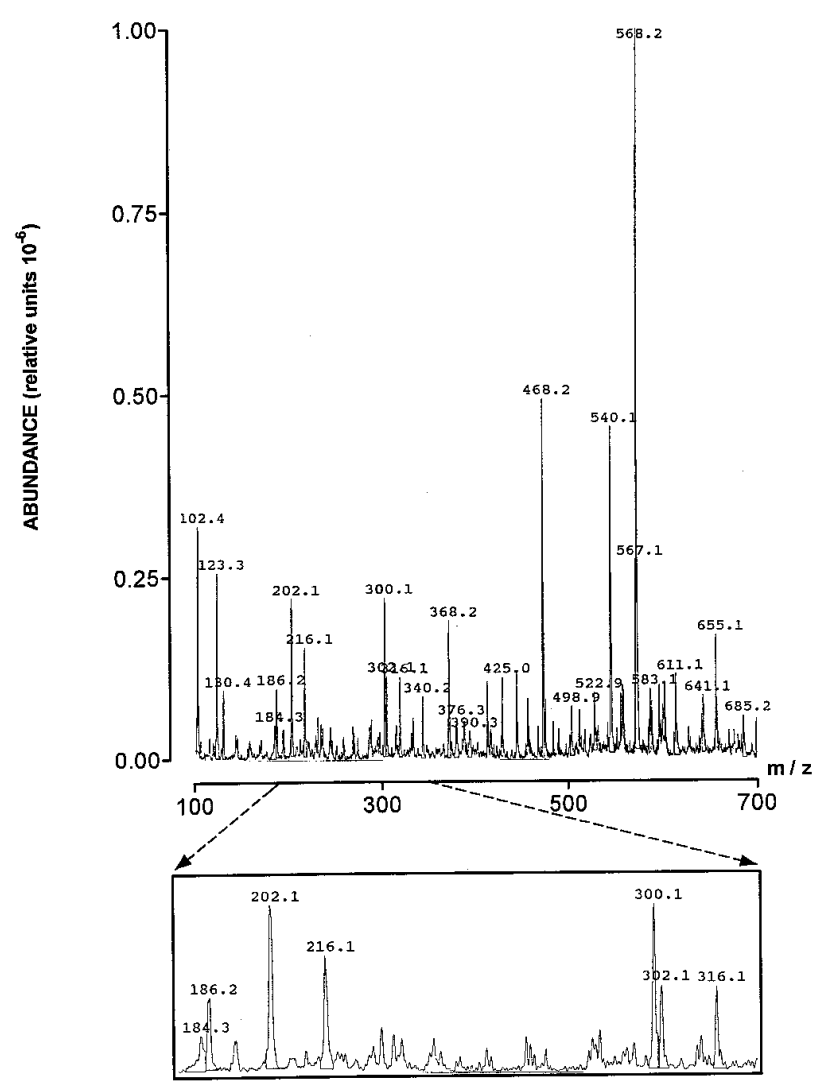

Fig. 4. Mass spectra of flavonoid extracts from $\mathrm{MgCl}_{2}$-infiltrated leaves. Flavonoids were extracted $48 \mathrm{~h}$ after infiltration and analysis was carried out in the 100 to $700 \mathrm{M}_{\mathrm{r}}$. A scale up of the 150 to $350 \mathrm{M}_{\mathrm{r}}$, is included. 
surrounding zone, whereas the noninfiltrated zone was the remaining part of the leaf blade.

Flavonoid content. The flavonoid content of the infiltrated and the noninfiltrated zones, extracted from leaflets harvested 48 and $96 \mathrm{~h}$ after infiltration with $P$. syringae pv. pisi, were analyzed by HPLC and the result obtained with the 48-h sample is presented in Figure 7. In the noninfiltrated zone (N.I.Z.), only compounds present also in the nontreated sample were found. In the infiltrated zone (Z.I.), however, all the flavonoids which were found to be produced during the incompatible interaction in the whole leaflets (Figs. 2 and 3), were accumulated. Similar results were obtained at $96 \mathrm{~h}$ (data not shown).

Gene expression. Total RNA from the infiltrated and noninfiltrated zones was extracted from leaflets harvested 3, 6, 9, and $24 \mathrm{~h}$ after infiltration with $P$. syringae pv. pisi, and accumulation of CHS, CHR, CHI, and IFR transcripts was analyzed by Northern blots (Fig. 8). None of the four transcripts was detectable in the control leaflets (C6). In the infiltrated zone, accumulation of all the four messenger RNA was observed, CHS and CHR transcripts accumulated transiently (maximum at $3 \mathrm{~h}$ ), whereas the $\mathrm{CHI}$ and IFR transcripts did

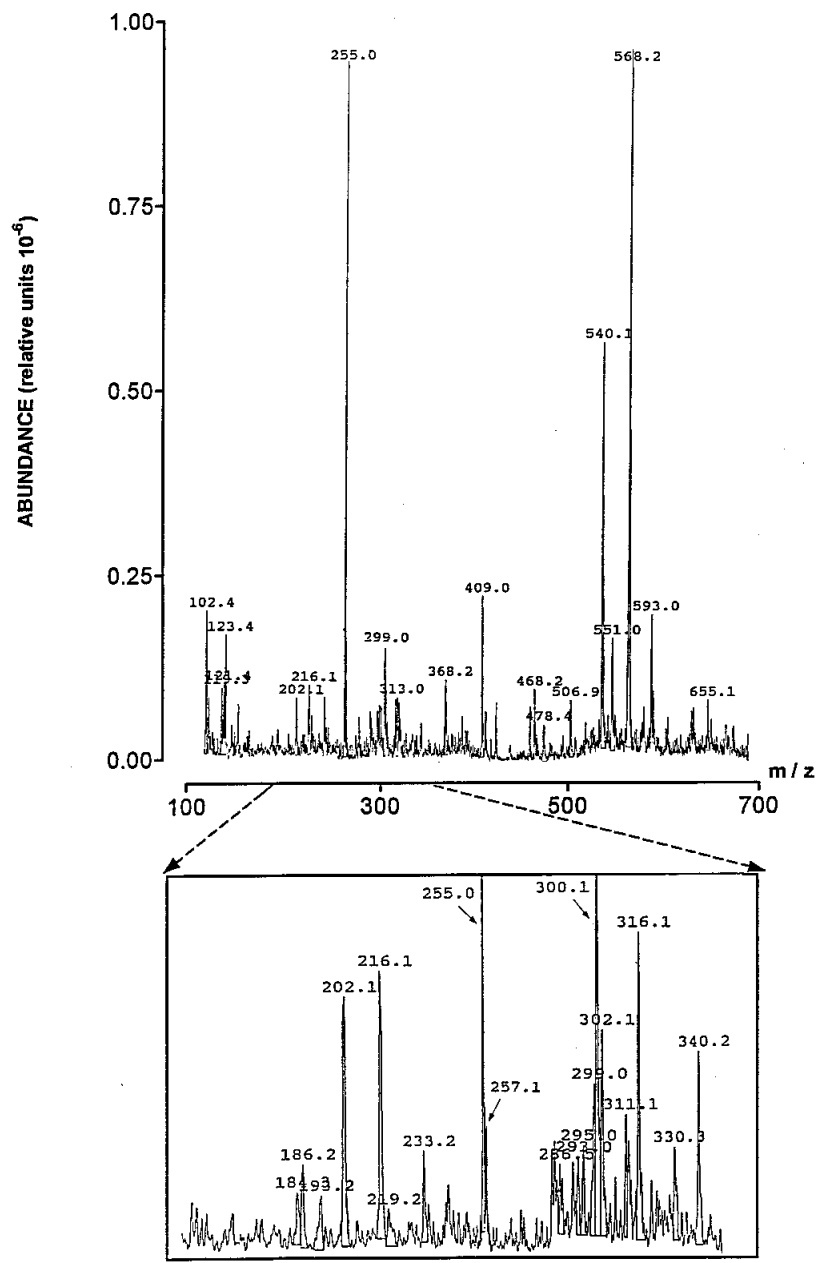

Fig. 5. Mass spectra of flavonoid extracts from leaves infiltrated with Pseudomonas syringae pv. pisi. Flavonoids were extracted $48 \mathrm{~h}$ after infiltration and analyzed in the 100 to $700 M_{\mathrm{r}}$. A scale up of the 150 to $350 M_{\mathrm{r}}$, is included. not level off (CHI) or only slightly (IFR). In the noninfiltrated tissue, again all the transcripts accumulated but with a slight delay as their maxima were at around $6 \mathrm{~h}$, then their level declined more rapidly than in the infiltrated zone.

Our results indicate that, in our experimental conditions, genes involved in the isoflavonoid pathway were expressed both in the infected as well as the healthy part of the leaf, whereas the flavonoids accumulated only in the infiltrated zone.

\section{Measurement of the CHS and IFR activities.}

To further substantiate the apparently divergent results obtained (accumulation of IFR transcripts vs. a very small amount of medicarpin, the expected phytoalexin) measurement of the IFR activity was necessary. In addition, the CHS activity in the same batches of plants was assayed. Determination of these enzymatic activities was carried out as described by Edwards and Kessmann (1992) for IFR and Claudot and Drouet (1992) for CHS, by using whole control (infiltrated with $\mathrm{MgCl}_{2}$ ) or treated (infiltrated with $P$. syringae) leaves, as well as, in this latter case, the infiltrated (I.Z.) and noninfiltrated (N.I.Z.) zones. The time course of the IFR and CHS activities are presented in Table 1. One important

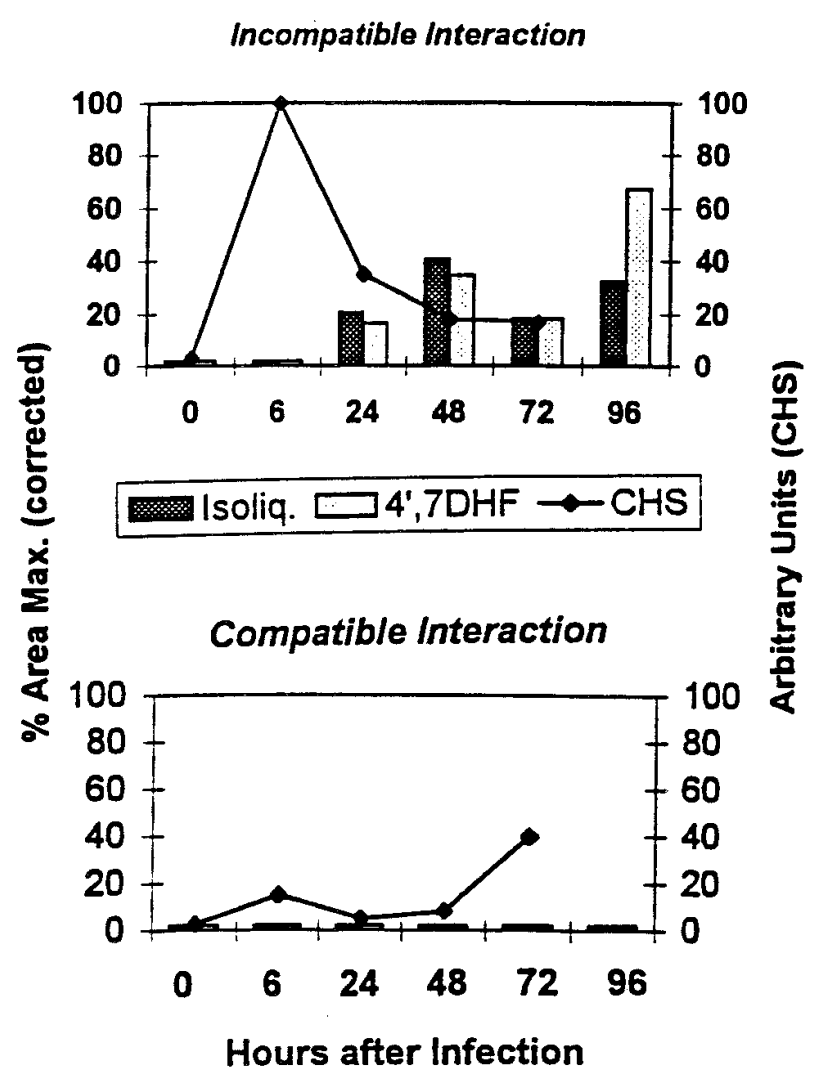

Fig. 6. Kinetics of the relative accumulation of 4'7-dihydroxy-flavone (4',7DHF), 4',7-dihydroxychalcone (Isoliq.) and CHS transcripts in leaves infiltrated with a suspension of Pseudomonas syringae pv. pisi (incompatible interaction) or Xanthomonas campestris pv. alfalfae (compatible interaction). The amounts of flavonoids were calculated from the size of the area of the peaks from the HPLC chromatograms divided by the respective extinction coefficient; each calculated value was then expressed as percent of the maximum value, i.e., (4',7DHF + Isoliq.) at the time point $96 \mathrm{~h}$. The CHS accumulation values are from densitometric readings of the Northern blots. 
point appearing from these data is the very low activity of IFR during the incompatible interaction; the peak corresponding to the product (vestitone) was actually a minor one corresponding to less than $2 \%$ of the substrate (see footnotes to Table 1). In the case of CHS the activity was high. The second striking characteristic of these data is that for both IFR and CHS, the measured activities were significantly higher in the infiltrated zone as compared to the noninfiltrated zone and more rapid. Significant IFR and CHS activities were detected only 30 (CHS) or $48 \mathrm{~h}$ (IFR) after infection. The maximum values obtained in our experimental conditions were compared to those obtained with alfalfa cultured cells, though the two experiments are not directly comparable. As a matter of fact for cultured cells the measured activities (expressed in Tkat $\mathrm{kg}_{\text {pro- }}$ tein $^{-1}$ ) for IFR were 5 (control) and 170 (elicited, Paiva et al. 1991) and for CHS 0.063 (control) and 0.183 (elicited, Kessmann et al. 1990). Whereas in our experimental system the degree of stimulation of the CHS activity was comparable to that of elicited cultured cells, the stimulation of the IFR activity was considerably lower.

These data are in agreement with the nature of the major accumulated compounds (4',7-dihydroxyflavone and 2',4,4'-
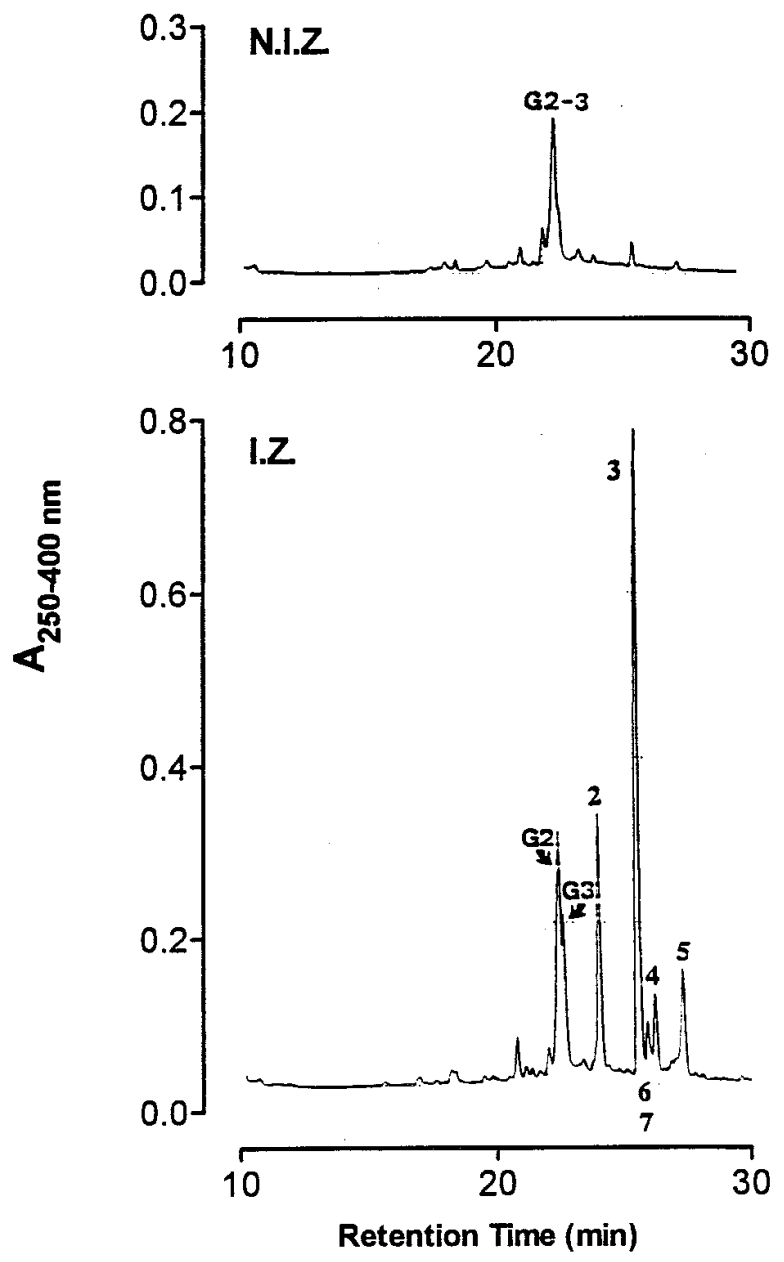

Fig. 7. HPLC chromatograms of total extracts from the noninfiltrated (N.I.Z.) and the infiltrated (I.Z.) zones with a suspension of Pseudomonas syringae pv. pisi. Leaves were harvested $48 \mathrm{~h}$ after the treatment. Conditions and numbering of the peaks are as in Figure 2. trihydroxychalcone) and the fact that medicarpin was produced as a minor compound (Fig. 2).

\section{Biological activity of the accumulated flavonoids.}

The accumulation of compounds belonging to the flavone group in the alfalfa leaves, in response to infiltration with a bacterium leading to an incompatible interaction, raised the question of their antimicrobial activity. Therefore, we tested the effects of the accumulated flavonoids, i.e., 4',7dihydroxyflavone and 2',4,4'-trihydroxychalcone, separately at 1,5 , and $10 \mu \mathrm{M}$ concentrations, on the growth of $P$. syringae pv. pisi and $X$. campestris pv. alfalfae. The growth of the bacterial populations was determined, as described in Materials and Methods, over a period of $30 \mathrm{~h}$ and for two starting densities, i.e., $10^{4}$ or $10^{6}$ bacteria $\mathrm{ml}^{-1}$. As shown in Figure 9, at $10 \mu \mathrm{M}$, none of the treatments significantly affected the bacterial growth. Moreover we did not detect any effect even when these compounds were mixed at a concentration of 5 $\mu \mathrm{M}$ each (data not shown).

\section{DISCUSSION}

In this study, we have detected several flavonoids accumulating during an incompatible interaction triggered in alfalfa leaves by the bacterium $P$. syringae pv. pisi. These flavonoids accumulated between 6 and $24 \mathrm{~h}$ postinfection and were not detectable in the compatible interaction with $X$. campestris pv. alfalfae up to at least $96 \mathrm{~h}$. Medicarpin, which has been described as the main phytoalexin produced in cultured alfalfa cells (Dalkin et al. 1990) and leaves (Smith et al. 1971) infected with pathogenic fungi, was only found at a very low level in the incompatible interaction or in the control leaves.

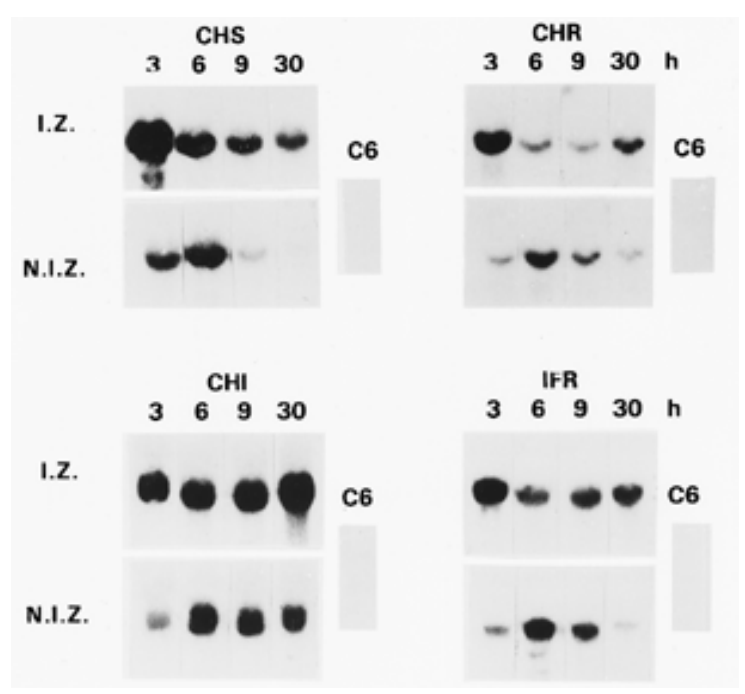

Fig. 8. Accumulation of CHS, CHR, CHI, and IFR transcripts in the infiltrated (I.Z.) and noninfiltrated (N.I.Z.) zones cut off from leaves after injection of a suspension of Pseudomonas syringae pv. pisi. Bacteria were infiltrated at $10^{9}$ bacteria $\mathrm{ml}^{-1}$ and Northern blots of total RNA populations ( $20 \mu \mathrm{g} / \mathrm{lane}$ ), isolated $3,6,9$, and $24 \mathrm{~h}$ after infiltration, were probed with alfalfa MsCHS1, CHR, CHI, and IFR cDNA clones. The control (C6) consisted of total RNA extracted from leaves harvested $6 \mathrm{~h}$ after infiltration with $10 \mathrm{mM} \mathrm{MgCl}$. The amount of RNA samples used for the Northern was quantified by staining the same filter with methylene blue which allowed the visualization of the cytosolic (25 and $18 \mathrm{~S}$ ) and chloroplastic (23 and $16 \mathrm{~S}$ ) rRNA. 
We did not find coumestrol, which has been reported to be accumulated in alfalfa leaves after infection by the fungus Ascochyta imperfecta (Olah and Sherwood 1971). These results suggest that flavonoid production induced in planta by fungi or bacteria may be differentially controlled. Other explanations can be a rapid turnover and/or metabolization of the synthesized medicarpin by the bacteria as, in our experimental conditions (Esnault et al. 1993), the number of bacteria increased only on the first day then remained nearly constant for the next 15 days.

From our previous analysis of the incompatible interaction with P. syringae pv. pisi (Esnault et al. 1993) we concluded that there was an apparently coordinated expression of several genes involved in the flavonoid branch pathway. However,

Table 1. Measurements of the IFR and CHS activities in M. sativa whole leaves, in infiltrated (I.Z.) and noninfiltrated (N.I.Z.) zones after infiltration with $\mathrm{MgCl}_{2}$ (control) or $P$. syringae pv. pisi ${ }^{\mathrm{a}}$

\begin{tabular}{|c|c|c|c|c|c|c|}
\hline & \multicolumn{3}{|c|}{ IFR } & \multicolumn{3}{|c|}{ CHS } \\
\hline & Whole leaf & N. I. Z. & I. Z. & Whole leaf & N. I. Z. & I. Z. \\
\hline To & 1.4 & I & I & 0.010 & 1 & I \\
\hline $\mathrm{MgCl}_{2}-17 \mathrm{~h}$ & 0.9 & I & I & 0.014 & I & l \\
\hline $\mathrm{MgCl}_{2}-30 \mathrm{~h}$ & 1.7 & I & I & 0.029 & I & I \\
\hline $\mathrm{MgCl}_{2}-48 \mathrm{~h}$ & 2.5 & I & I & 0.009 & I & I \\
\hline P.s. $-48 \mathrm{~h}$ & 13.8 & I & I & 0.193 & I & I \\
\hline P.s. $-9 \mathrm{~h}$ & I & 1 & 1 & I & 0.008 & 0.072 \\
\hline P.s. $-17 \mathrm{~h}$ & I & 5.4 & 8.3 & I & 0.005 & 0.087 \\
\hline P.s. $-30 \mathrm{~h}$ & I & 1.3 & $19.7^{\mathrm{b}}$ & I & 0.025 & $0.293^{\mathrm{c}}$ \\
\hline P.s. $-48 \mathrm{~h}$ & I & 8.9 & 17.4 & I & I & I \\
\hline
\end{tabular}

${ }^{a}$ The presented data are typical values from 3 independent experiment and are expressed in $\mu \mathrm{kat}^{\mathrm{kg}} \mathrm{protein}^{-1}$. Measurements not done are indicated by a /.

${ }^{\mathrm{b}}$ Value corresponding to the transformation of $1.7 \%$ of the substrate

${ }^{c}$ Value corresponding to the transformation of $14.8 \%$ of the substrate.

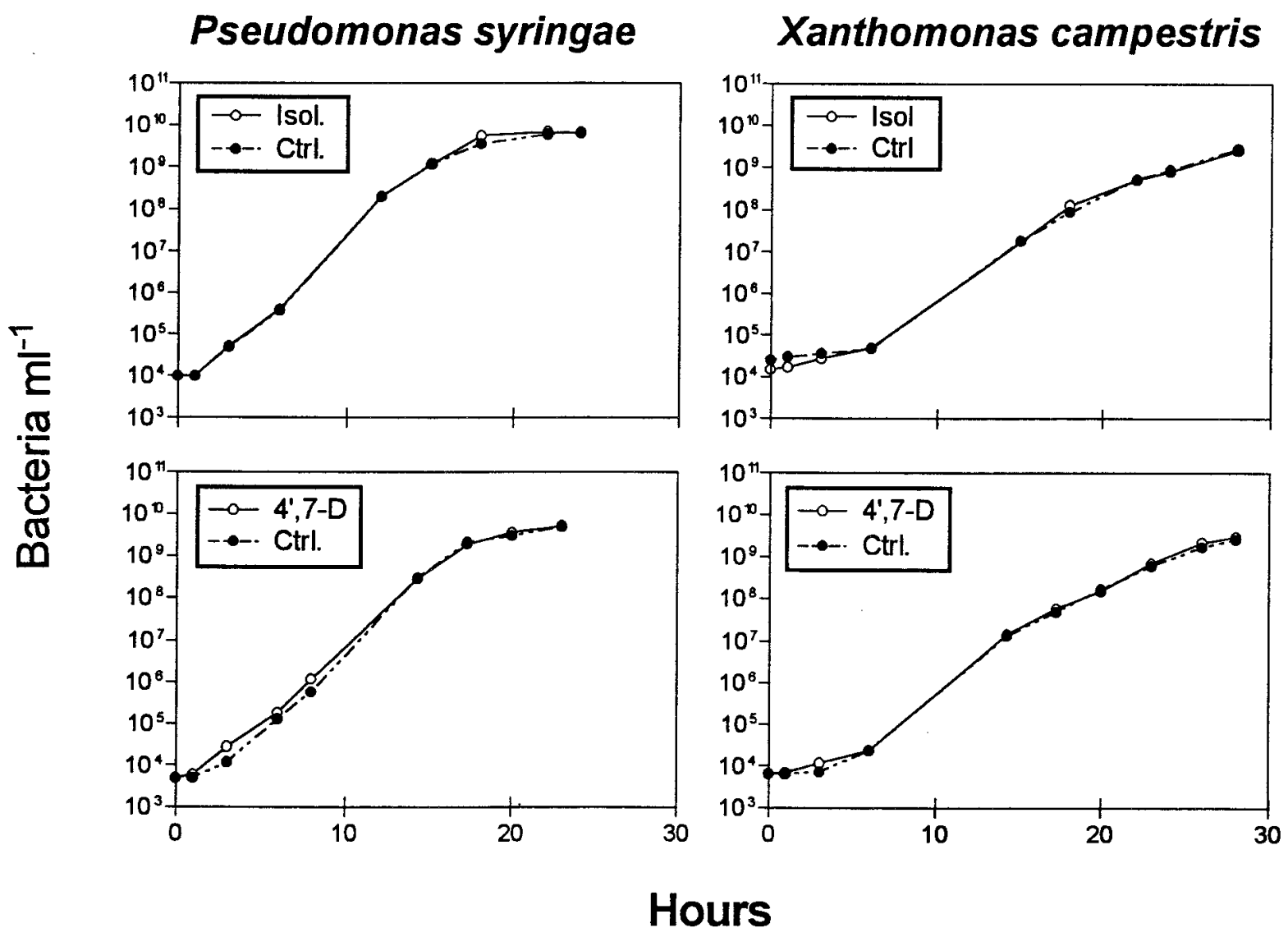

Fig. 9. Effects of $2^{\prime}, 4,4^{\prime}$-trihydroxychalcone (Isol.) and $4^{\prime}, 7$-dihydroxyflavone (4',7-D) on the growth of Pseudomonas syringae pv. pisi and Xanthomonas campestris pv. alfalae. These compounds were used at $10 \mu \mathrm{M}$ concentrations by diluting stock solutions in $50 \%$ ethanol; the same volume of $50 \%$ ethanol was used for the control samples. The kinetic of growth was followed by measuring the absorbance at $409 \mathrm{~nm}$ of the liquid growth culture and by plating on solid medium. 
these studies were performed without distinguishing the infiltrated and noninfiltrated zones, the latter one representing in our experimental conditions around $40 \%$ of the leaflet blades. The analysis presented here allowed us to confirm and complement this conclusion; accumulation of the analyzed transcripts occurred both at the site of infection and in the noninfiltrated zone, albeit the expression of the four genes was slightly delayed and more transient in the noninfiltrated zone. Interestingly, $\mathrm{CHI}$ transcripts appeared to accumulate differentially than the other analyzed transcripts, CHS, CHR, IFR, since its level of accumulation did not level off (Fig. 8). In bean cell suspensions, the induction of CHI enzyme activity by an elicitor isolated from the bean pathogen Colletotrichum lindemuthianum lasted at least $24 \mathrm{~h}$, whereas the induction of the CHS enzyme activity was transient and decreased after $6 \mathrm{~h}$ (Robbins and Dixon 1984). These data suggest that during the defense reaction $\mathrm{CHI}$ gene transcription and $\mathrm{CHI}$ enzyme activity is differentially regulated from that of the other genes CHS, CHR, and IFR.

One of the main conclusions to be drawn from our results described in this paper, is that induction of the genes involved in the flavonoid pathway is not sufficient to lead to the accumulation of the expected final products. Two sets of data support this conclusion. First, according to the metabolic pathway shown in Figure 1, accumulation of medicarpin or its direct precursor (vestitone) or related derivatives (coumestrol, vestitol, or sativan) was expected but the major accumulated compounds were 4',7-dihydroxyflavone and to a lesser extent 4',7-dihydroxyflavanone and 2',4,4'-trihydroxychalcone. The relatively large amount of this chalcone is rather surprising as the likely high activity of CHI (as demonstrated in elicited cells, Dalkin et al. 1990) might immediately transform it to 4',7-dihydroxyflavanone. To settle this point it would be necessary to measure the CHS, CHR, CHI, FS, and IFS activities as the accumulation of these chalcone and flavanone reflects the efficiency (in terms of specific activity, velocity, and enzymatic regulation) of the various enzymes involved in their production. On the other hand, we did not detect any significant accumulation of intermediate compounds belonging to the isoflavonoid pathway (from daidzein to vestitone), suggesting a bypass of the branch at the IFS level. As far as vestitone (the product of IFR activity) and medicarpin (resulting from the vestitone transformation) are concerned, such a small accumulation can be explained by the observation (Table 1) of a very low stimulation of IFR activity in the leaves up to $48 \mathrm{~h}$ postinfection. These results were surprising as medicarpin was shown to accumulate in alfalfa cell suspensions treated with a fungal elicitor (Dalkin et al. 1990) and leaves (Smith et al. 1971) infected with pathogenic fungi. However, the absence of accumulation of coumarins, the major phytoalexins from parsley, was also observed (Kombrink and Hahlbrock 1986) when cultured parsley cells were treated with an extracellular polysaccharide from $X$. campestris resulting in a large increase of the phenylalanine amonia-lyase (PAL) and 4coumarate-CoA ligase (4CL) activities. In addition, in bean leaves inoculated with a saprophytic bacterium, Meier et al. (1993) have shown accumulation of CHS transcripts without production of phytoalexins. Our enzyme activity values measured in the infiltrated and noninfiltrated zones indicated that they were less stimulated during the incompatible interaction in the noninfiltrated zones. This is in agreement with our findings that, in our experimental conditions, no significant accumulation of flavonoids in the noninfected region of the leaf blades was detected.

The second argument supporting our conclusion is provided by the observation that accumulation of CHS, CHR, CHI, and IFR transcripts in the cells of the noninfiltrated zone did not lead to the synthesis of new flavonoids in this part of the leaf (Fig. 7). Moreover, no flavonoids were detected during the compatible interaction (Figs. 2 and 6), while we have shown that CHS, CHI, and IFR transcripts were, slightly but significantly, accumulated during this interaction (Esnault et al. 1993). Our results on flavonoid accumulation are in agreement with those of Meier et al. (1993) but differ in some aspects from their results on the induction of flavonoid biosynthetic genes. These authors have shown that during an interaction between bean leaf and an avirulent race of $P$. syringae pv. phaseolicola, flavonoids were accumulated in the infiltrated zone, whereas PAL, CHS, and chitinase transcripts were detected in the inoculation site (defined as zone 1) and, albeit to a lesser extent, in the surrounding 5- to 7-mm zone (defined as zone 2) and not at all in the remainder part of the leaf (zone $3)$. In our experimental conditions, the injected zone corresponded to zones 1 and a part of zone 2 and was, in fact, a chimera of alive and necroting cells, whereas the noninjected zone was equivalent to zone 3 (as defined by these authors). These topological differences might be related to the interacting plant/pathogen partners as well as the concentration of the injected bacterial suspensions which were different. Nevertheless, our conclusion is in agreement with the observations made on the analysis of expression of a bean CHS promoter linked to the E. coli $\beta$-glucuronidase reporter gene in transgenic tobacco (Stermer et al. 1990). In the HR induced by the $P$. syringae, the highest level of GUS was observed in healthy cells around the infected tissue, whereas lower but still elevated levels were seen throughout the leaf, decreasing with distance from the infection site. Our results suggest the existence of a local systemic induction of genes involved in both the early (CHS, CHR, CHI) and late (IFR) steps of the flavonoid biosynthetic pathway.

We cannot ascertain that the flavonoids specifically accumulated in alfalfa leaves in response to the infiltration of a suspension of incompatible bacteria are really antimicrobial agents. This is in agreement with our previous results (Esnault et al. 1993) showing that the $P$. syringae pv. pisi population infiltrated in the leaves, increased 100 times in the infiltrated zone in 1 day and thereafter remained roughly constant up to 15 days postinfection. If the accumulated flavonoids behave as phytoalexins, they should be static rather than toxic agents (Smith 1982). Another interesting question is the actual concentrations of the detected flavonoids in the cells at the infection site. Microspectrophotometry might help to answer such a question if possible interferences due to various phenolic compounds, formed in response to the ingress of pathogens (Nicholson and Hammerschmidt 1992), could be eliminated.

Our results indicate that the induction of the expression of genes involved in the flavonoid biosynthetic pathway is not a sufficient condition for the production of phytoalexins during plant/pathogen interactions. It seems that one or several posttranscriptional steps are essential in determining the nature of the flavonoids or phytoalexins accumulated during these interactions. Events affecting mRNA (for example, stability or 
translational efficiency) or posttranslational modifications of the polypeptides as well as enzymatic regulation might be involved in the qualitative and/or quantitative control of the flavonoid production.

\section{MATERIALS AND METHODS}

\section{Chemicals.}

2',4,4'-trihydroxychalcone, 4',7-dihydroxyflavanone, 4',7dihydroxyflavone and formononetin (7-hydroxy-4'-methoxyisoflavone) were purchased from Extrasynthese SA (BP62 ZI Lyon Nord, 69730 Genay, France), 2'-hydroxyformononetin and 7,2'-dihydroxy-4'methoxyisoflavanone (vestitone) from Plantech (The University, Reading RG1 5AQ, England) and biochanin A (5,7-dihydroxy-4'methoxyisoflavone) from Sigma Chemical Co. Medicarpin was a gift from W. Barz (University of Westfälische, W-4400 Münster, Germany). Two lots of coumaroyl CoA have been used: The first was a gift from R. Edwards (University of Durham, England) and the second was synthesized by A. Lamouri (Université de Paris 7, France).

\section{Bacterial strains and growth conditions.}

Pseudomonas syringae pv. pisi (provided by J. Schmidt, INRA, Versailles) and Xanthomonas campestris pv. alfalfae (provided by R. E. Stall, University of Florida) were grown at $30^{\circ} \mathrm{C}$ in YDA medium (glucose $10 \mathrm{~g} \mathrm{liter}^{-1}$, yeast extract $5 \mathrm{~g}$ liter $^{-1}$ and peptone [Difco] $5 \mathrm{~g} \mathrm{liter}^{-1}$ ). When treated with flavonoids compounds, aliquots of flavonoid stock solutions in $50 \%$ ethanol were added into the medium containing the bacterial suspension either at $10^{4}$ or $10^{6}$ bacteria liter $^{-1}$, to give the appropriate final concentration. The same $50 \%$ ethanol volume was used for the control samples. The kinetics of growth was followed by measuring the absorbance at $409 \mathrm{~nm}$ and plating on YDA medium, solidified with $1.5 \%$ agar (Difco).

\section{Injection of plants.}

Alfalfa plants (Medicago sativa ssp. sativa cv. Nagyszénàsi) were grown in culture chambers as previously described (Esnault et al. 1993). Plant leaves were injected with $P$. syringae pv. pisi and $X$. campestris pv. alfalfae as previously described (Esnault et al. 1993). Control leaves were infiltrated with a $10 \mathrm{mM} \mathrm{MgCl}_{2}$ solution.

For some experiments, the noninfiltrated and infiltrated zones were harvested. These two zones were, respectively, defined as the injected area per se, easily distinguishable just after infiltration and delimited with a black marker, plus the 1 to $2 \mathrm{~mm}$ surrounding zone, and the remainder of the leaf blade.

\section{Northern blot analysis.}

Total RNA was isolated from leaves by the guanidium thiocyanate-CsCl purification method according to Sambrook et al. (1989). Total RNA (25 $\mu \mathrm{g})$ was denatured in $50 \%$ formamide, $6 \%$ formaldehyde at $65^{\circ} \mathrm{C}$, separated by electrophoresis through a $6 \%$ formaldehyde gel $(1.2 \%$ agarose) and transferred onto Hybond $\mathrm{N}$ (Amersham) nylon membrane by capillary blotting according to the manufacturer's protocol. Total RNA was quantified spectrophotometrically before loading, and equal loading of RNA was checked after electro- phoresis and transfer onto the membrane by staining the membrane with methylene blue (Sambrook et al. 1989). RNA blots were hybridized with $\left[{ }^{32} \mathrm{P}\right]$-labeled cDNA inserts (Megaprime system: Amersham) at $42^{\circ} \mathrm{C}$ in $50 \%$ formamide, according to the manufacturer's instructions. Each Northern analysis was carried out at least three times. The probes used were alfalfa MsCHS1, a cDNA coding for chalcone synthase (Esnault et al. 1993), MsCHR1a, a cDNA coding for chalcone reductase (Sallaud et al. 1995a), alfalfa pCHI, a cDNA coding for chalcone isomerase (McKhann and Hirsh 1994) and pIFRalf1, a cDNA coding for isoflavone reductase (Paiva et al. 1991), kindly provided by H. McKhann and R. A. Dixon, respectively.

\section{Flavonoid isolation.}

Leaves $(500 \mathrm{mg})$ were frozen and ground in liquid nitrogen. The powder was mixed with an internal standard (200 $\mu \mathrm{l}$ of biochanin A at $0.1 \mathrm{mM}$ ) and flavonoids were extracted with 10 $\mathrm{ml}$ of $80 \%$ cold acetone. After centrifugation at $3000 \times g$, the supernatant was dried with $\mathrm{N}_{2}$ gas stream $\left(50^{\circ} \mathrm{C}\right)$, dissolved in $1 \mathrm{ml}$ of $80 \%$ ethanol and adsorbed to $\mathrm{C}_{18}$ Maxi-Clean cartridges. Flavonoids were eluted with $1.5 \mathrm{ml}$ of $80 \%$ ethanol, dried with $\mathrm{N}_{2}$ gas stream $\left(50^{\circ} \mathrm{C}\right)$, and dissolved in $500 \mu \mathrm{l}$ of $80 \%$ ethanol. These samples, called total extract in the text, contain total flavonoids, i.e., glycosylated and nonglycosylated flavonoids. For the separation of the aglycones (nonglycosylated flavonoids), the ethanol fraction was dried and dissolved in $3 \mathrm{ml}$ of $\mathrm{H}_{2} \mathrm{O}$ which were extracted three times with an equivalent volume of ether. Then the ether fraction was evaporated under $\mathrm{N}_{2}$ gas stream and the pellet was resuspended in $80 \%$ ethanol. These fractions contained the aglycones. The total flavonoids and aglycones were analyzed by HPLC.

\section{Analytical HPLC.}

Aliquots $(15 \mu \mathrm{l})$ were loaded onto a Waters HPLC system (Millipore Corp., New Bedford, MA) fitted with a $3.9 \times 150$ mm Nova-pack C18-4 $\mu \mathrm{m}$ column, preceded by a guardcolumn. Elution was at $1 \mathrm{ml} \mathrm{min}^{-1}$ from 0 to $60 \mathrm{~min}$ with a linear gradient from 20:80:0.1 to $80: 20: 0.1$ (v/v/v) methanol:water:trifluoroacetic acid (or as specified in the text, Fig. 3). From 60 to $70 \mathrm{~min}$ a linear gradient from 80:20:0.1 to 0:100:0.1 ( $/ \mathrm{v} / \mathrm{v})$ was applied and the analysis was then continued isocratically for another $5 \mathrm{~min}$. Eluted compounds were monitored with a Waters 991 photodiode array detector, which measured absorbance ( 200 to $400 \mathrm{~nm}$ ) every $2 \mathrm{~s}$ with a $5-\mathrm{nm}$ resolution.

\section{Enzyme assays and protein determination.}

Protein extracts were prepared from $1 \mathrm{~g}$ of frozen leaf blades. IFR and CHS activity measurements were carried out as described by Edwards and Kessmann (1992) and Claudot and Drouet (1992), respectively. The CHS assay was based on the incorporation of $\left[2-{ }^{14} \mathrm{C}\right]$ malonyl-CoA into a nonpolar product $\left(2^{\prime}, 4,4^{\prime}\right.$-trihydroxychalcone), extracted from the aqueous phase with ethyl acetate; radioactivity of the organic phase was determined by scintillation counting. Separation of the product from the substrate was checked by TLC. The IFR assay was carried out by HPLC analysis allowing the separation of the product (vestitone) from the substrate (2'hydroxyformononetin). For quantification of the vestitone 
produced, commercially purchased vestitone was used as external standard. The HPLC analyses were carried out by using a Shimadzu LC-6A apparatus fitted with a Nova-pack C18 column (see above) and the same chromatographic conditions as for the analytical analysis. Eluted compounds were monitored with a Shimadzu UV-visible SPD-6AV spectrometer and chromatograms treated with the Class Unipac, release 1.2, software (Shimadzu). Protein concentration in the extracts was determined using the Bio-Rad Protein Assay Dye Reagent according to the manufacturer's specifications using BSA as a standard.

\section{Mass spectrometry analyses.}

The analyzed samples were the total extracts as described in the paragraph "Flavonoid isolation." The mass spectra were obtained on a Nermag R10/10 quadrupole mass spectrometer (Quad Service, Poissy, France) fitted with an Analytica of Branford (Branford, CT) electrospray source. Samples were introduced continuously through the electrospray interface with an Harvard syringe pump (S. Natick, Massaschusetts) at a rate of $1 \mu \mathrm{min}^{-1}$. The following instrument settings were used: potential difference of $4.5 \mathrm{kV}$ applied between the grounded needle and the ends of the capillary; $\mathrm{N}_{2}$ heated to $50^{\circ} \mathrm{C}$ as drying gas. Positive ions spectra were acquired in profile mode by scanning from 100 to 700 uma.

\section{ACKNOWLEDGMENTS}

We wish to express their gratitude to R. A. Dixon (Plant Biology Division, Samuel Roberts Noble Foundation, Ardmore, OK, U.S.A.), H. McKhann (University of California, Los Angeles, U.S.A.) for providing isoflavone reductase and chalcone isomerase cDNA clones, respectively. We thank R. Edwards (University of Durham, UK) for providing coumaroyl CoA samples used in our initial work and A. Lamouri (Université Paris 7, France) for synthesizing this compound used in our further experiments. We are indebted to the Commission of the European Countries (BRIDGE BIOT-900159-C) for research support, and the Quad Service Co. (Poissy, France) for the realization of the mass spectrometry analysis.

\section{LITERATURE CITED}

Baker, C. J., O’Neill, N. R., and Tomerlin, R. J. 1989. Accumulation of phenolic compounds in incompatible clone/race interactions of Medicago sativa and Colletotrichum trifolii. Physiol. Plant Pathol. 35:231241.

Bailey, J. A. 1982. Mechanism of phytoalexin accumulation. Pages 289318 in: Phytoalexins. J. A. Bailey and J. W. Mansfield, eds. Blackie, Glasgow.

Claudot, A.-C., and Drouet, A. 1992. Preparation and assay of chalcone synthase from walnut tree tissue. Phytochemistry 31:3377-3380.

Collinge, D. B., and Slusarenko, A. J. 1987. Plant gene expression in response to pathogens. Plant Mol. Biol. 9:389-410.

Dalkin, K., Edwards, R., Edington, B., and Dixon, R. A. 1990. Stress responses in alfalfa (Medicago sativa L.) I. Induction of phenylpropanoid biosynthesis and hydrolytic enzymes in elicitor-treated cell suspension cultures. Plant Physiol. 92:440-446.

Darvill, A. G., and Albersheim, P. 1984. Phytoalexins and their elicitors: A defense against microbial infection in plants. Annu. Rev. Plant Physiol. 35:243-275.

Dewick, P. M., and Martin, M. 1979a. Biosynthesis of pterocarpan, isoflavan and coumestan metabolites of Medicago sativa: Chalcone, isoflavone and isoflavanone precursors. Phytochemistry 18:597-602.

Dewick, P. M., and Martin, M. 1979b. Biosynthesis of pterocarpan and isoflavan phytoalexins in Medicago sativa: The biochemical interconversion of pterocarpans and 2'-hydroxyisoflavans. Phytochemistry 18:591-596.

Dixon, R. A., and Lamb, C. J. 1990. Molecular communication in inter- actions between plants and microbial pathogens. Annu. Rev. Plant. Physiol. 41:339-367.

Edwards, R., and Kessmann, H. 1992. Pages 45-62 in: Molecular Plant Pathology. A Practical Approach, Vol. II. S. J. Gurr, M. J. McPherson, and D. J. Bowles, eds. IRL Press, Oxford.

Esnault, R., Buffard, D., Breda, C., Sallaud, C., El-Turk, J., and Kondorosi, A. 1993. Pathological and molecular characterizations of alfalfa interactions with compatible and incompatible bacteria, Xanthomonas campestris pv. alfalfae and Pseudomonas syringae pv. pisi. Mol. Plant-Microbe Interact. 6:655-664.

Higgins, V. J. 1972. Role of the phytoalexin medicarpin in three leaf spot diseases of alfalfa. Physiol. Plant Pathol. 2:289-300.

Keen, N. T. 1992. The molecular biology of disease resistance. Plant Mol. Biol. 19:109-122.

Kessmann, H., Choudhary, A. D., and Dixon, R. A. 1990. Stress responses in alflafa (Medicago sativa L.) III. Induction of medicarpin and cytochrome P450 enzyme activities in elicitor-treated cell suspension cultures and protoplasts. Plant Cell Rep. 9:38-41.

Kombrink, E., and Hahlbrock, K. 1986. Responses of cultured parsley cells to elicitors from phytopathogenic fungi: Timing and dose dependency of elicitor-induced reactions. Plant Physiol. 81:216-221.

Latunde-Dada, A. O., Dixon, R. A., and Lucas, J. A. 1987. Induction of phytoalexin biosynthetic enzymes in resistant and susceptible lucerne callus lines infected with Verticillium alboaltrum. Physiol. Mol. Plant Pathol. 31:15-23.

Mansfield, J. W. 1982. The role of phytoalexins in disease resistance. Pages 253-288 in: Phytoalexins. J. A. Bailey and J. W. Mansfield, eds. Blackie, Glasgow.

Martin, M., and Dewick, P. M. 1980. Biosynthesis of pterocarpan, isoflavan and coumestan metabolites of Medicago sativa: The role of an isoflav-3-ene. Phytochemistry 19:2341-2346.

Maxwell, C. A., Hartwig, U. A., Joseph, C. M., and Phillips, D. A. 1989. A chalcone and two related flavonoids released from alfalfa roots induce nod genes of Rhizobium meliloti. Plant Physiol. 91:842-847.

Mayama, S., and Tani, T. 1982. Microspectrophotometric analysis of the location of avenalumin accumulation in oat leaves in response to fungal infection. Physiol. Plant Pathol. 21:141-149.

McKhann, H. I., and Hirsh, A. M. 1994. Isolation of chalcone synthase and chalcone isomerase cDNAs from alfalfa (Medicago sativa L.): Highest transcript levels occur in young roots and root tips. Plant Mol. Biol. 24:767-777.

Meier, B. M., Shaw, N., and Slusarenko, A. J. 1993. Spatial and temporal accumulation of defense gene transcripts in bean (Phaseolus vulgaris) leaves in relation to bacteria-induced hypersensitive cell death. Mol. Plant-Microbe Interact. 6:453-466.

Moesta, P., and Grisebach, H. 1982. L-2-Aminooxy-3-phenylpropionic acid inhibits phytoalexin accumulation in soybean with concomitant loss of resistance against Phytophthora megasperma f. sp. glycinea. Physiol. Plant Pathol. 21:65-70.

Nicholson, R. L., and Hammerschmidt, R. 1992. Phenolic compounds and their role in disease resistance. Annu. Rev. Phytopathol. 30:369389.

Olah, A. F., and Sherwood, R. T. 1971. Flavones, isoflavones, and coumestans in alfalfa infected by Ascochyta imperfecta. Phytopathology 61:65-69.

O’Neill, N. R., and Saunders, J. A. 1994. Compatible and incompatible responses in alfalfa cotyledons to races 1 and 2 of Colletotrichum trifolit. Phytopathology 84:283-287.

Paiva, N. L., Edwards, R., Sun, Y., Hrazdina, G., and Dixon, R. A. 1991 Stress response in alfalfa (Medicago sativa L.). 11. Molecular cloning and expression of alfalfa isoflavone reductase, a key enzyme of isoflavonoid phytoalexin biosynthesis. Plant. Mol. Biol. 17:653-667.

Robbins, M. P., and Dixon, R. A. 1984. Induction of chalcone isomerase in elicitor-treated bean cells. Comparison of rates of synthesis and appeareance of immunodetectable enzyme. Eur. J. Biochem. 145:195202.

Sallaud, C., El-Turk, J., Bigarré, L., Sevin, H., Welle, R., and Esnault, R. 1995a. Nucleotide sequences of three chalcone reductase genes from alfalfa. Plant Physiol. 108:869-870.

Sallaud, C., El-Turk, J., Breda, C., Buffard, D., de Kozak, I., Esnault, R., and Kondorosi, E. 1995b. Differential expression of cDNA coding for chalcone reductase, a key enzyme of the 5-deoxyflavonoid pathway, under various stress conditions in Medicago sativa. Plant Sci. 109:179-190. 
Sambrook, J., Fritsch, E. F., and Maniatis, T. A. 1989. Molecular Cloning: A Laboratory Manual. 2nd ed. Cold Spring Harbor Laboratory, Cold Spring Harbor, NY.

Smith, D. A. 1982. Toxicity of phytoalexins. Pages 218-252 in: Phytoalexins. J. A. Bailey and J. W. Mansfield, eds. Blackie, Glasgow.

Snyder, B. A., Leite, B., Hipskind, J., Butler, L. G., and Nicholson, R. L. 1991. Accumulation of sorghum phytoalexins induced by Colle- totrichum graminicola at the infection site. Physiol. Mol. Plant Pathol. 39: 463.470 .

Stermer, B. A., Schmid, J., Lamb, C. L., and Dixon, R. A. 1990. Infection and stress activation of bean chalcone synthase promoters in transgenic tobacco. Mol. Plant-Microbe Interact. 3:381-388.

Templeton, M. D., and Lamb, C. J. 1988. Elicitors and defense gene activation. Plant Cell Environ. 11:395-401. 